\title{
Analysis of Movement and Rhythmic Skills in Physical Education Students
}

\author{
Sri Sundari ${ }^{1 *}$, Nofi Marlina Siregar ${ }^{2}$, Ramdan Pelana $^{3}$ \\ ${ }^{1}$ Universitas 17 Agustus 1945 Cirebon \\ ${ }^{2 \& 3}$ Universitas Negeri Jakarta \\ *Corresponding author.Email: srisundari2727@gmail.com
}

\begin{abstract}
The aim of this article is to assess students of Physical Education, FKIP University on 17 August 1945, Cirebon' s level of movement and rhythmic skills. The studied sample included 50 PJKR students with a total sampling at the FKIP UNTAG Cirebon. Descriptive statistical analysis has been used to analyze the data obtained. The results from this study show that the breath value of the male specimen is 77,9 on average, 77,8 on average, 78,6 on average and 79,5 on a single aspect. The average movement performance value of the male student sample was 78,5, with an average of 87,5 for the female sample, $86,25,86,67$ and 87,5 for the individual. For the female student sample, the average total performance is 87 points.
\end{abstract}

Keywords-rhythmic activity, skills, physical education.

\section{INTRODUCTION}

As a subject in the physical education curriculum of the Faculty of Teacher Training and Education Universitas 17 August 1945 Cirebon, Motion and Rhythmic Learning has a relatively large responsibility where this course is the only subject that is responsible for providing movement and rhythmic competence to students of the Education Study Program. Physical. Movement and rhythm have become two things that combine with each other in physical education activities in the school curriculum, ranging from elementary to senior high, however, the portion given to these activities is still relatively small compared to other movement activities. We can see movement activities combined with this rhythm or rhythm in various activities in the school environment both in the corridors of physical education lessons and outside the context of imprisonment.

Rhythmic activities are one of the important materials in the school physical education curriculum. Through rhythmic activities, children can develop motor skills and creativity (Modoran, 2014). According to research by Kwon et al. (2016), rhythmic activity can improve balance and reduce depression. In addition, rhythmic activity also has an important effect on endurance, strength, cardiovascular endurance, flexibility and lung capacity (Barney \& Prusak, 2015). Rhythmic activity is also a type of physical activity that combines motor skills to aid physical fitness and provides students with more active lifestyle choices (Little \& Hall, 2017).
A brief review of the literature indicates that some studies attempt to identify useful indicators for talent identification and training development plans, but they describe each parameter separately: anthropometric characteristics (e.g., (Alessandra Di Cagno et al., 2008, 2009), physiological parameters (Alessandra Di Cagno et al., 2013), or explosive strength (Alessandra Di Cagno et al., 2013). (Douda et al., 2008). Hume (1993) describes several predictors of achievement in rhythmic sports (physical, psychological, and training measures for sports performance), and Rutkauskait and Skarbalius (2018), Rutkauskait and Skarbalius (2018), and Rutkauskait and Skarbalius (2012) lay the groundwork for optimizing training for rhythmic sports (Rutkauskaitè \& Skarbalius, 2018c, 2018a, 2018b).

Within the scope of physical education we can see the movements and artistic activities in rhythmic gymnastics, traditional dance movements, etc., however the movements and artistic activities that we usually see are not within the scope of physical education, for example; marching activities, ceremonies, sports such as Scouting means moving from one point to another, and rhythm is simply defined as rhythmic regularity. Physical exercise itself has a very close relationship with a person's mental health (Carless \& Douglas, 2010).

The rhythmic gymnastics in the gymnastics curriculum itself is one of the branches of overall gymnastics, and together with other gymnastics branches, it becomes the ability material for physical education students. This is related to the rapid development of the community's rhythm activity business. Rhythmic activities that are popular in the community are varied, from physical exercises for elementary school students (SKJ), aerobic exercises to other rhythmic activities. Aerobic exercise is part of rhythmic gymnastics. Generally, aerobic exercises can be divided into the following two types: low-impact aerobic exercises, gymnasts' foot exercises never leave the floor, while highimpact aerobic exercises are exercises for gymnasts that leave the floor and jump a lot. , Jump a lot, and various operations (Surahni, 2017).

One of these goals in Physical Education itself is in order to provide students with basic abilities in having a healthy lifestyle, and one of the activities that can be carried out related to the goal is dancing or dancing, or other 
activities that are rhythmic. One of the ways that can be done in schools related to the health of students is; Increase the portion of physical activity for children, incorporate music into these activities, choose songs and music that are in accordance with the development of students, use simple tools or instruments in physical activity, do physical activity in a large enough room, invite parents to participate in the activity, choose a song and ask the child to make a movement according to the song's lyrics. (Izumi-Taylor et al., 2012).

This is one of the qualities that Physical Education graduates must possess in order to be employed in the school where they will teach in the future. As a result, students must be able to carry out the role of motion with time and time correctly in the course of motion and rhythmic movements themselves. One factor becomes the primary criterion for determining how the motion and rhythmic outcome. The term "posture" refers to the body's relative location, which is commonly associated with a static or resting position. The orientation of the body in relation to its position on the floor, whether standing upright, bent over, squatting, lying down, and so on, is referred to as posture (Australian Sports Commission, 2007). The symmetrical form of the body in the sagittal plane, which divides the body into two parts right and left, and the center of the body mass, which is exactly in the middle when a straight line is drawn from head to foot, are also indicators of good posture.

\section{METHODS}

This study was carried out using descriptive instruments and techniques for collecting data in order to then measure and record the results of the correct measurement of the results of the assessment of students who were given different learning methods based on the characteristics of the learning that was taking place. The variables investigated in this study were the level of student skills in movement and rhythmic activities, and the sample used was all students in the Motion and Rhythmic Learning course of the Physical Education Study Program FKIP UNTAG Cirebon 2019, as many as 50 people who were taken using a total sampling instrument, where the entire target population was used as a random research sample.

The research constellation's data collection techniques are variable data that support the quality of movement skills of students in Motion and Rhythmic Learning courses. The following data components were collected at the end of the Motion and Rhythmic Learning course process: 1) Beat Score, 2) Body Form, 3) Movement Value, and 4) Movement Value. 4) Performance Rating, 5) Overall Score, 6) Music Score, 7) Choreography Score, and 8) Group Video Score. The variable data gathered serves as a benchmark for the level of student skills in following the lecture process, as well as a component of the practicum assessment at the end of the semester's learning process. The students' skill level in the practice of learning motion and rhythm is an accumulation of the variables whose data is collected in the data collection process.

The research instrument is a variable student understanding of the steps of basic gymnastic movement skills assessed through a survey method with a motion and rhythmic assessment rubric instrument containing the skill component points. Motion and rhythmic learning competencies are lecture load competencies. The collected research data is processed and analyzed statistically, which includes calculating the average value, standard deviation, centralizing, and distributing data.

\section{RESULTS AND DISSCUSSION}

According to the descriptive analysis results, the research sample with the male gender obtained a minimum score of 67.5 and a maximum score of 97.5. Meanwhile, the male sample beats average is 77.9 , the body form average is 77.8 , the motion value is 78.6 , and the individual appearance average is 79.5 . The average value of the male student sample's performance of motion is 78.5. The result of the research sample's minimum score with the female gender is 67.5 , and the highest score is at a maximum score of 100 . While the average score of the female sample beats is 87.5 , body form is 86.25 , movement is 86.67 , and individual appearance is 87.5 . The female student sample's average overall performance is 87 points.

Research has yet to determine a model for and interaction with rhythmic athletes of different ages and sports performance (based on and specific) (training and sports performance) (Rutkauskaitė \& Skarbalius, 2018c, 2018a, $2018 b$ ). In verifying the parameters that are relevant indicators and their contribution to the successful performance of rhythm-gymnastics, we have guidelines for identifying, selecting, developing and promoting talent, as have been described by other authors (A. Di Cagno et al., 2008; Alessandra Di Cagno et al., 2008, 2009, 2013).

\section{CONCLUSION}

The proportion of the total sample of males and females is 88.5 percent compared with 11.5 percent. The average results of the research on individual movement and rhythm variables for women were better than the results of the male sample with a ratio of 87 points for the average overall performance score for female students and 78.5 points for the overall appearance results of male students. This study revealed that the average skills possessed by female students were better than male students with an average difference of 8.5 points on a scale of 100 .

\section{REFERENCES}

Barney, D., \& Prusak, K. A. (2015). Effects of Music on Physical Activity Rates of Elementary Physical Education Students. Physical Educator. 
Carless, D., \& Douglas, K. (2010). Sport and Physical Activity for Mental Health. In Sport and Physical Activity for Mental Health. https://doi.org/10.1002/9781444324945

Di Cagno, A., Baldari, C., Battaglia, C., Brasili, P., Merni, F., Piazza, M., Toselli, S., Ventrella, A. R., \& Guidetti, L. (2008). Leaping ability and body composition in rhythmic gymnasts for talent identification. Journal of Sports Medicine and Physical Fitness.

Di Cagno, Alessandra, Baldari, C., Battaglia, C., Guidetti, L., \& Piazza, M. (2008). Anthropometric characteristics evolution in elite rhythmic gymnasts. Italian Journal of Anatomy and Embryology.

Di Cagno, Alessandra, Baldari, C., Battaglia, C., Monteiro, M. D., Pappalardo, A., Piazza, M., \& Guidetti, L. (2009). Factors influencing performance of competitive and amateur rhythmic gymnastics-Gender differences. Journal of Science and Medicine in Sport. https://doi.org/10.1016/j.jsams.2008.01.006

Di Cagno, Alessandra, Sapere, N., Piazza, M., Aquino, G., Iuliano, E., Intrieri, M., \& Calcagno, G. (2013). ACE and AGTR1 polymorphisms in elite rhythmic gymnastics. Genetic Testing and Molecular Biomarkers. https://doi.org/10.1089/gtmb.2012.0209

Douda, H. T., Toubekis, A. G., Avloniti, A. A., \& Tokmakidis, S. P. (2008). Physiological and anthropometric determinants of rhythmic gymnastics performance. International Journal of Sports Physiology and Performance. https://doi.org/10.1123/ijspp.3.1.41

Izumi-Taylor, S., Morris, V. G., Meredith, C. D., \& Hicks, C. (2012). Music and Movement for Young Children's Healthy Development. Dimensions of Early Childhood.

Little, S., \& Hall, T. (2017). Selecting, Teaching and Assessing Physical Education Dance Experiences. Journal of Physical Education, Recreation \& Dance. https://doi.org/10.1080/07303084.2016.1260075

Modoran, M. (2014). Methodological Approaches Specific to Rhythmical Music Education in the Romanian Primary School. Procedia - Social and Behavioral Sciences. https://doi.org/10.1016/j.sbspro.2014.01.726

Rutkauskaite, R., \& Skarbalius, A. (2018a). Interaction of Training and Performance of 13-14-Year-Old Athletes in Rhythmic Gymnastics. Baltic Journal of Sport and Health https://doi.org/10.33607/bjshs.v3i82.318

Rutkauskaitè, R., \& Skarbalius, A. (2018b). Models and Interaction of Intensive Training and Sport Performance of 14-15-Year-Old Athletes in Rhythmic Gymnastics. Baltic Journal of Sport and Health Sciences. https://doi.org/10.33607/bjshs.v4i87.258

Rutkauskaitè, R., \& Skarbalius, A. (2018c). Training and Sport Performance of the 11-12 Year Old Athletes in Rhythmic Gymnastics. Baltic Journal of Sport and Health https://doi.org/10.33607/bjshs.v1i72.459

Surahni. (2017). Pendidikan Jasmani, Olahraga dan Kesehatan (PJOK) sebagai Sarana Pendidikan Moral. The 6th University Research Colloquium 2017. 